\title{
EDDP Measurement
}

National Cancer Institute

\section{Source}

National Cancer Institute. EDDP Measurement. NCI Thesaurus. Code C75353.

The determination of the amount of EDDP, the primary metabolite of methadone, present in a sample. 